\title{
In situ X-ray tomography observation of inhomogeneous deformation in semi-solid aluminium alloys
}

\author{
S. Terzi, ${ }^{\text {a }}$ L. Salvo, ${ }^{\text {a }}$ M. Suéry, ${ }^{\mathrm{a}, *}$ N. Limodin, ${ }^{\mathrm{b}}$ J. Adrien, ${ }^{\mathrm{b}}$ E. Maire, ${ }^{\mathrm{b}}$ Y. Pannier, ${ }^{\mathrm{c}}$ \\ M. Bornert, ${ }^{c}$ D. Bernard, ${ }^{\mathrm{d}}$ M. Felberbaum, ${ }^{\mathrm{e}}$ M. Rappaz ${ }^{\mathrm{e}}$ and E. Boller ${ }^{\mathrm{f}}$ \\ ${ }^{a}$ Grenoble INP, SIMaP/GPM2, UMR CNRS 5266, UJF, BP46, 38402 Saint-Martin d'Hères Cedex, France \\ ${ }^{\mathrm{b}}$ Université de Lyon, INSA-Lyon, MATEIS, UMR CNRS 5510, 7 Avenue Jean Capelle, F-69621 Villeurbanne, France \\ ${ }^{\mathrm{c}}$ LMS, Ecole Polytechnique, UMR CNRS 7649, 91128 Palaiseau, France \\ ${ }^{\mathrm{d}}$ ICMCB, UPR CNRS 9048, 87 Av du Dr. A. Schweitzer, 33608 Pessac Cedex, France \\ ${ }^{\mathrm{e}}$ Laboratoire de Simulation des Matériaux, Ecole Polytechnique Fédérale de Lausanne, MXG-STI, Station 12, \\ CH-1015 Lausanne, Switzerland \\ ${ }^{\mathrm{f}}$ ESRF, 6 rue Jules Horowitz, BP220, 38043 Grenoble Cedex, France
}

\begin{abstract}
The aim of this paper is to report the very first in situ observations of the deformation behaviour of an Al-Cu alloy in the semisolid state by using ultrafast, high-resolution X-ray microtomography. It is shown that this deformation is non-homogeneous and involves an accumulation of liquid at an intergranular surface nearly perpendicular to the strain axis. Once the liquid is no longer able to feed such a region, micropores form and grow at this surface, finally leading to a crack.
\end{abstract}

Keywords: In situ X-ray tomography; Aluminium alloys; Semi-solid state; Deformation; Pores

During the solidification of alloys, various regimes of rheological behaviour have been described in the literature [1-3]; these involve several transitions, depending primarily on the type of mechanical interactions between the solid grains and on the ability of the liquid to flow in between the grains. In particular, at large solid fractions, continuous liquid films remain at grain boundaries and this situation is critical for the hot tearing phenomenon. Indeed, in this range, the local volume change accompanying solidification cannot be fed by intergranular liquid, and therefore pores nucleate and grow along grain boundaries, leading to the formation of hot tears.

The prediction of hot tearing requires knowledge of, on the one hand, the constitutive behaviour of the alloy while it solidifies [4], and, on the other hand, criteria for its formation $[5,6]$. Until now, these criteria have suffered from two main limitations: (i) they usually do not consider any localization (of strains or feeding) and (ii) they are based on observations carried out after complete solidification on "cold" specimens. In addition

\footnotetext{
*Corresponding author. E-mail: Michel.Suery@simap.grenoble-inp.fr
}

to conventional methods, X-ray tomography $[7,8]$ has been used recently to characterize hot tears in three dimensions. The only in situ observations of hot tearing formation were performed on transparent analogue alloys $[9,10]$. Although such alloys can mimic the solidification of metallic alloys (e.g. formation of dendrites), they do not have the same mechanical behaviour and the strain and strain rate were not carefully controlled in these experiments.

Strong X-ray beams now available at several synchrotron facilities open new perspectives for the study of hot tear formation. Recently, in situ observations of the evolution of the microstructure of aluminium alloys were carried out during solidification and partial remelting by using ultrafast X-ray microtomography at ESRF Grenoble [11-13].

In the present study, we report the first in situ X-ray tomography observations of tensile deformation in semi-solid specimens. For that purpose, a tensile testing machine was specifically designed to be fitted on the Xray beam line. This high-temperature tensile rig is rather similar to that described in Ref. [14]. The specimen of $\mathrm{Al}-8 \mathrm{wt} . \% \mathrm{Cu}$ alloy was a cylinder of $2 \mathrm{~mm}$ in diameter and $8 \mathrm{~mm}$ in length, the extremities of which were in- 
serted into alumina tubes and fixed with ceramic glue. In order to localize the deformation of the specimen in the region of interest where X-ray images are recorded, the cross-section of the specimen was locally reduced to about $1.5 \mathrm{~mm}$ in diameter (i.e. a notched zone). The specimen was heated by an induction coil and the temperature was controlled and monitored by using a thermocouple $0.5 \mathrm{~mm}$ in diameter inserted into the lower alumina tube and in close contact with the specimen. The specimen was heated at $0.5^{\circ} \mathrm{C} \mathrm{s}^{-1}$ up to $555^{\circ} \mathrm{C}$, i.e. above the eutectic temperature $\left(548^{\circ} \mathrm{C}\right)$, and then held isothermally for $3 \mathrm{~min}$ at this temperature to reach thermal homogenization. The tensile test was then performed at a displacement speed of $0.1 \mu \mathrm{m} \mathrm{s}^{-1}$ which leads to an average strain rate equal to $2 \times 10^{-4} \mathrm{~s}^{-1}$, assuming that the gauge length of the specimen is equal to $0.5 \mathrm{~mm}$.

During the tensile test, the tensile rig and the specimen were allowed to rotate through $180^{\circ}$ in $16 \mathrm{~s}$, while the heating coil itself was fixed. During this rotation, 400 transmission images of the zone of interest of the specimen were recorded. The pixel size was set to $2.8 \mu \mathrm{m}$. Such scans of the specimen were recorded every $27 \mathrm{~s}$ using the latest version of the Camera FReLoN F2kHD-Atmel with a fast readout of the CCD camera set at 20 Mpixels s$^{-1}$ [15]. After data acquisition, three-dimensional (3-D) images of the specimen were reconstructed using standard reconstruction tools. In addition to direct post-processing of these images to quantify the evolution of the microstructure, specific volumetric digital image correlation (V-DIC) has been applied to measure 3-D displacement fields in the bulk of the specimen, from which local strain heterogeneities have been derived. A specific procedure has been developed to compute local strains from sparsely distributed displacement measurement points located at solid-liquid interfaces $[16,17]$.

Figure 1 shows a sequence of four 3-D images of the notched area taken at various times during deformation.
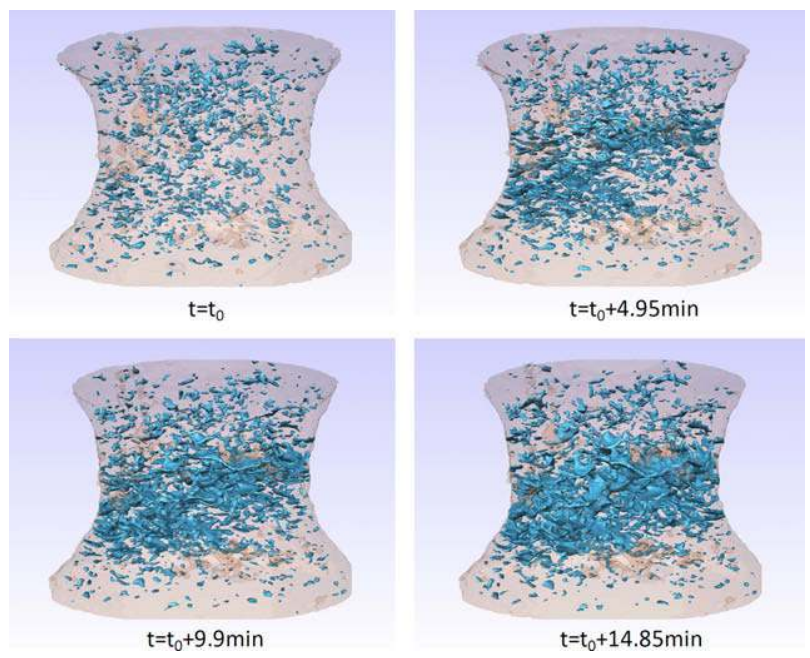

Figure 1. Sequence of 3-D images of the notched zone of the specimen after various deformation times. The figure shows the variation of the liquid volume fraction in this zone (blue regions). (For interpretation of colour mentioned in this figure, the reader is referred to the web version of this article.)
The liquid regions have been outlined in blue. At the onset of deformation, time $t_{0}$, the liquid of near-eutectic composition is fairly homogeneously distributed within the whole specimen. The measured volume fraction of liquid, typically $7-8 \%$, can be compared to the theoretical value predicted by two microsegregation models. At the temperature of $555{ }^{\circ} \mathrm{C}$, the liquid fraction is equal to $9 \%$ under equilibrium conditions, whereas the ScheilGulliver model gives $17 \%$. The measured value is closer to the equilibrium value, which seems to indicate that the heating plus holding times were sufficient to homogenize the initial copper concentration profiles of the solidified specimen. However, perfect homogenization should not be achieved if one calculates the corresponding Fourier number $F_{O}\left(F_{O}<0.1\right)$. Furthermore, the measured liquid fraction is even lower than the equilibrium value. This can be explained by the fact that some of the liquid remains in the form of intergranular films which are too thin to be detected by X-ray tomography.

The next three images of Figure 1 show the same notched region at various times (or levels) of deformation. As deformation proceeds, the fraction of liquid in the deformed zone increases. In other words, since the solid skeleton experiences plastic deformation with $\nabla \cdot v_{\mathrm{s}}>0$, liquid flows into the notched region (i.e. $\left.\nabla \cdot v_{\ell}<0\right)$ in order to ensure global mass conservation. At the longest time (i.e. about $900 \mathrm{~s}$ or $18 \%$ average deformation of the specimen) a few pores or cracks have already appeared in the notched area. This is shown in more detail in Figure 2, where a sequence of 2-D images has been extracted from the 3-D reconstructed views of

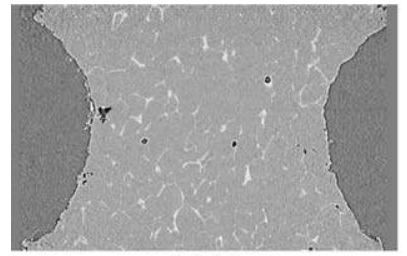

(a) $t=t_{0}$

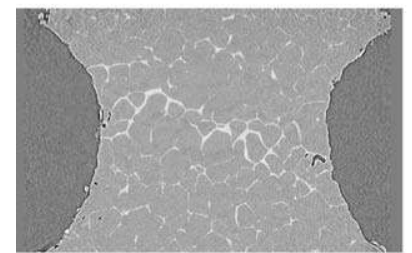

(c) $t=t_{0}+9 \min$

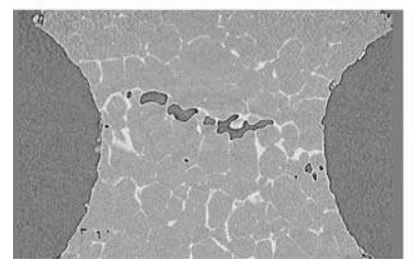

(e) $t=t_{0}+18 \mathrm{~min}$

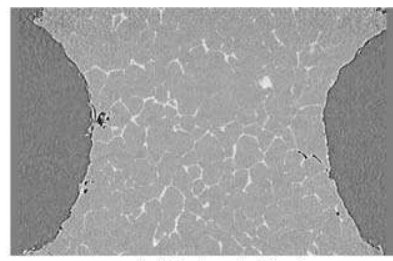

(b) $t=t_{0}+4.5 \mathrm{~min}$

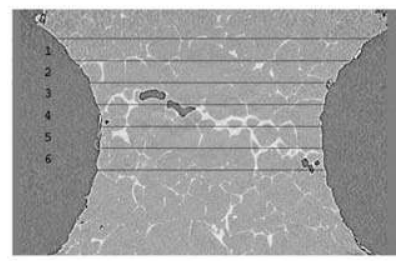

(d) $t=t_{0}+13.5 \mathrm{~min}$

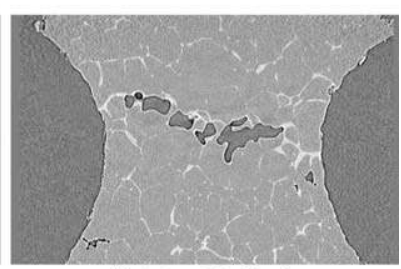

(f) $t=t_{0}+22.5 \mathrm{~min}$
Figure 2. Sequence of 2-D images obtained from the 3-D reconstructed views of the notched area of the specimen. The tensile axis is vertical and the time after deformation is applied at time $t_{0}$ is indicated in each figure. In order to evaluate local strains at various positions along the sample, six horizontal slices (average vertical height of about $125 \mu \mathrm{m})$ have been defined and are indicated in (d). 
the notched zone for a section parallel to the tensile direction. Before deformation is applied to the specimen, the liquid (white areas) is homogeneously distributed and a few isolated pores are initially present (black areas) (Fig. 2a). After $9 \mathrm{~min}$ of deformation (Fig. 2c), the liquid tends to accumulate in the centre of the notched area and a "liquid path" has formed across the reduced section, nearly perpendicularly to the applied stress. Fluid motion and grain rearrangement/deformation are also revealed by the shrinking of the small isolated pores that were present in Figure $2 \mathrm{a}$ and $\mathrm{b}$.

In order to assess more quantitatively the gradual inhomogeneous distribution of liquid in the specimen during deformation, six horizontal slices have been defined (labelled 1-6 and identified in Fig. 2d). These slices are about $125 \mu \mathrm{m}$ thick and are selected such that slices 4 and 5 are symmetric on each side of the narrowest transverse section of the notch. Similarly, Sections 3 and 6 are also symmetric. In the central part of the notch (slices 4 and 5), the volume fraction of liquid was estimated to increase up to $25 \%$ when the local average equivalent strain reached about 10\% (Fig. 2c). Since deformation is carried out isothermally, the total liquid fraction in the overall sample is constant under equilibrium conditions. Therefore, the increase in the volume fraction of liquid near the centre of the notch, which is much larger than that given by lever rule or even by the Scheil-Gulliver equation, is made at the expense of adjacent regions which become depleted in liquid. However, this is not clearly revealed by the direct observation of Figure 2. Again, this can be explained by the low resolution of the tomography, which did not allow the detection of the thin liquid films before deformation. This hypothesis is confirmed by the evolution of the average volume change (as determined by V-DIC) of each of the six transverse slices defined in Figure 2d. As shown in Figure 3, the central zone of the specimen (slices 4 and 5), where deformation is the highest, experiences a volumetric expansion. Sections 3 and 6, which are also symmetric about the notch, show differing behaviour at the onset of deformation but exhibit nearly the same expansion after $15 \mathrm{~min}$. Finally, Section 2 shrinks throughout the deformation period, whereas Section 1 initially shrinks but subsequently experiences slight volumetric expansion.

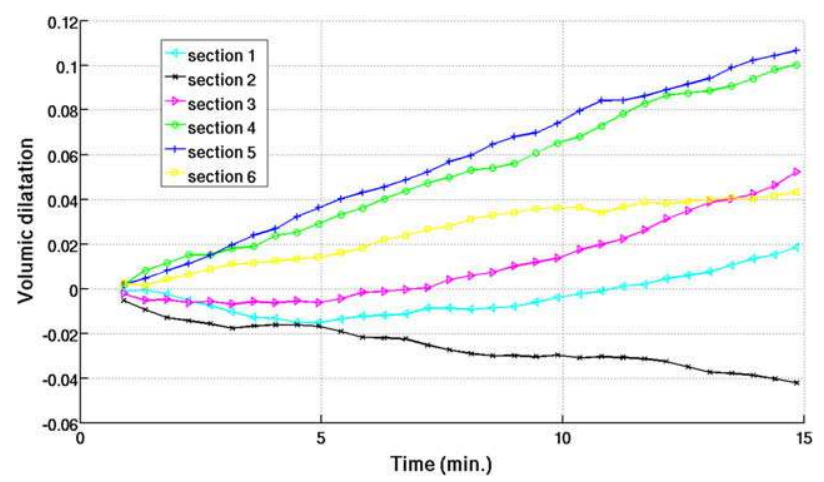

Figure 3. Evolution of the measured dilatation of the specimen in various transverse sections labelled 1-6 and identified in Figure 2d.
This complex behaviour of the semi-solid state is very different from that of a fully solid material strained at high temperature. If the elastic contribution is small or the Poisson coefficient is equal to 0.5 , deformation should occur at constant volume (i.e. $\nabla \cdot v_{\mathrm{s}}=0$ ). Because of the local heterogeneities of the microstructure (solid bonds between grains, thickness and connectivity of the liquid films, etc.), this is no longer the case at a solid volume fraction $g_{s} \approx 0.9$. In the weakest regions where dendrites (or grains) are pulled apart, liquid can flow in, leading to a volumetric expansion. This is done at the expense of other regions which are drained of their liquid.

After this first stage during which strain of the semisolid specimen is accommodated by liquid flow, solid grains may come into contact in the zones where $\nabla \cdot \boldsymbol{v}_{\mathrm{s}}<0$, precluding further volume compaction in such zones where $g_{s} \approx 1$. When these drained regions can no longer feed the liquid channel at the centre of the notch, further straining leads to the formation of pores. This can be observed in Figure 2d, 13.5 min after the beginning of straining. A pore located near the surface on the right side of the notch was already present in the specimen (see Fig. 2a-c) and has grown during deformation, but two "new" larger pores have appeared in the liquid channel in Figure 2d, at the level of slices 3 and 4. Considering that the liquid readily wets its own solid (the solid-liquid interfacial energy $\gamma_{\ell s}$ of aluminium is about one order of magnitude smaller than the gas-liquid interfacial energy $\gamma_{\ell g}$ ), it is easiest to nucleate and grow a pore in the widest liquid channel. As the specimen continues to be deformed, "new" pores form in the liquid channel at the centre of the notch, while existing ones grow (Fig. 2e and f). This array of pores following the path of what was the main liquid channel now appears as a partially cracked surface, with a few solid bridges remaining across the gap. It therefore exhibits all the features typically observed in hot tears in metallic or organic alloys $[9,10]$. However, as we are observing a longitudinal section, it is not certain whether "new" pores really nucleate in the liquid channel or are interconnected to existing ones through a tortuous 3-D path.

Figure 4 sheds some light on the interconnectivity of the pores formed at the level of the notch. This figure shows a 3-D view of the specimen cross-section after $22.5 \mathrm{~min}$ of deformation. Clearly, the pores seen in

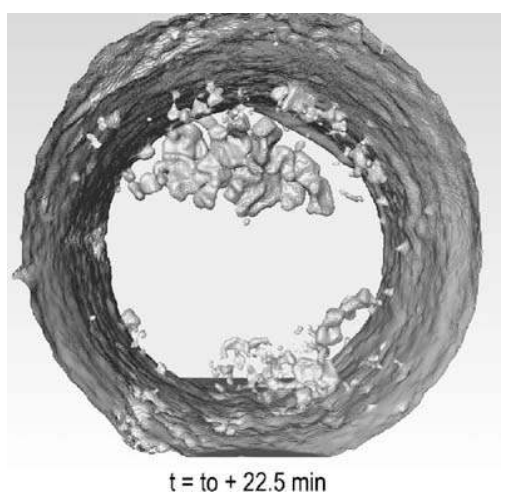

Figure 4. 3-D image seen from the top of the pores (in light grey) formed after $22.5 \mathrm{~min}$ of deformation. 
Figure 2 (and which are light grey in Figure 4) are in fact interconnected in three dimensions. They form along a surface (appearing as a channel in two dimensions) nearly perpendicular to the tensile axis and where liquid accumulates during the early stage of deformation.

In situ X-ray tomography observations, performed under isothermal conditions, have clearly demonstrated that deformation of a semi-solid material is highly inhomogeneous and the solid and liquid phases reorganize themselves throughout. In particular, the remaining liquid initially accumulates in a region where strains are highest and the solid skeleton is undergoing expansion, i.e. at an intergranular surface nearly perpendicular to the tensile axis. There is a global mass conservation so that regions undergoing expansion are fed by other regions where the solid is becoming compacted. Once these last regions are drained of their liquid, pores form in the region where nucleation and propagation is the easiest, i.e. in the intergranular region where the liquid layer is thickest. These pores, which appear disconnected in a 2-D metallographic section, are in fact interconnected and propagate as a void across the liquid surface. These observations clearly demonstrate the power of high-resolution X-ray tomography for the in situ study of hot tear formation in semi-solid alloys, and open new routes of investigations.

This work was carried out in the framework of the project ANR-05-BLAN-0286-01 "TOMOSOLIDAL" supported by the Agence Nationale de la Recherche, which is gratefully acknowledged. The authors thank all staff members of the ID19 beam line of ESRF Grenoble for their technical support.
[1] A.K. Dahle, L. Arnberg, JOM 48 (1996) 34.

[2] A.K. Dahle, D.H. St. John, Acta Mater. 47 (1999) 31.

[3] A.K. Dahle, S. Instone, T. Sumitomo, Metall. Mater. Trans. 34A (2003) 105.

[4] O. Ludwig, J.-M. Drezet, Ch. Martin, M. Suéry, Metall. Mater. Trans. 36A (2005) 1525.

[5] M. M'Hamdi, A. Mo, H.G. Fjaer, Metall. Mater. Trans. 37A (2006) 3069.

[6] M. Rappaz, M. Gremaud, J.-M. Drezet, Metall. Mater. Trans. 30A (1999) 449.

[7] A. Phillion, S. Cockcroft, P. Lee, Scr. Mater. 55 (2006) 489.

[8] A.B. Phillion, S.L. Cockcroft, P.D. Lee, Mater. Sci. Eng. A 491 (2008) 237.

[9] P.D. Grasso, PhD Thesis 3037, Ecole Polytechnique Fédérale de Lausanne, Switzerland, 2004.

[10] I. Farup, J.-M. Drezet, M. Rappaz, Acta Mater. 49 (2001) 1261.

[11] O. Ludwig, M. DiMichiel, L. Salvo, M. Suéry, P. Falus, Metall. Mater. Trans. 36A (2005) 1515.

[12] N. Limodin, L. Salvo, M. Suéry, M. DiMichiel, Acta Mater. 55 (2007) 3177.

[13] N. Limodin, L. Salvo, E. Boller, M. Suéry, M. Felberbaum, S. Gailliègue, K. Madi, Acta Mater. 57 (2009) 2300.

[14] J.-Y. Buffière, E. Maire, P. Cloetens, G. Lormand, R. Fougères, Acta Metall. Mater. 47 (1999) 1613-1625.

[15] J.-C. Labiche, O. Mathon, S. Pascarelli, M.A. Newton, G.G. Ferre, C. Curfs, G. Vaughan, A. Homs, D.F. Carreiras, Rev. Sci. Instrum. 78 (2007) 091301.

[16] Y. Pannier, M. Bornert, Volumetric Digital Image Correlation Adapted to Images with a Spatially Non Uniform Contrast, Euromat 2007, Nürenberg, 10-13 September 2007.

[17] Y. Pannier, M. Bornert, Adapted Volumetric-DIC for Images with Sparse Local Contrast, Photomechanics 2008, Loughborough, 7-9 July 2008. 